\title{
No early prospects of decision on future flights
}

\section{Washington}

As the debate over how and whether to pay for a new space shuttle rages at the White House, the National Aeronautics and Space Administration (NASA) is trying to give shape to the agency's future in the post-Challenger era.

In testimony last week before the House Science and Technology Committee, NASA acting administrator William Graham made it clear that shuttle flights are unlikely to resume before next January. NASA estimates it will cost $\$ 350$ million over the next two years for "anomaly resolution activities".

NASA is already launched on an exhaustive safety analysis of shuttle systems. Although the presidential panel investigating the Challenger accident has yet to establish a cause, Graham conceded that changes in the solid rocket booster would probably be necessary and it would be "appropriate" to redesign the seal rings.

Even if the $\$ 2,800$ million needed for a new shuttle is found, $\$ 750$ million of which must come from the already tight 1987 budget, NASA will be able to operate only three shuttles between now and 1990 . NASA plans to move slowly after shuttle flights resume, exacerbating the accumulating payload backlog. Graham hopes that commercial interests will operate expendable launch vehicles to relieve some of the burden on the shuttle, but he admitted that the current budget contains no money to help start such ventures.

Although members of the House committee are clearly anxious to allocate funds for building a new shuttle, a source close to the White House senior interagency group responsible for making a decision about the shuttle says no answer is likely until June, when the presidential panel makes its report. The interagency group is also wrestling with the thorny problem of which government agencies should be paying for shuttle services. The debate is being carried on by mid-level bureaucrats, but agency chiefs will soon be joining in.

Several members of the committee expressed concern that NASA might encourage potential shuttle customers to look elsewhere for launch services. But Graham confirmed that a proposal to carry the British Skynet satellites aboard the shuttle had already been terminated. With 32 launch commitments already on the books, Graham argued that NASA could not commit itself to others until the future of the shuttle was clear.

When flights do resume, priority will be given to those carrying payloads "critical to national security priorities", followed by scientific launches with fixed launch windows, and finally all other flights specifically needing the capabilities of the shuttle. Both the Galileo mission (see below) and Ulysses, the European Space Agency (ESA) mission to explore the Sun's polar regions, have launch windows in June 1987, but Graham doubted that both could then be launched.

No matter what decisions are made about the shuttle, NASA plans to go ahead with the manned space station programme as scheduled. It is expecting to sign agreements shortly covering the parts of the space station on which Canada and Japan will work. Japan has been studying a multipurpose pressurized module, while Canada is developing a remote manipula- tor system. But an agreement with ESA over European participation has hit a snag, and NASA administrators are working feverishly to hammer out an agreement before the end of March, when an engineering meeting will establish the space station baseline configuration.

As acting administrator, Graham has presided over NASA during its most difficult time. The agency's reputation has suffered as much of a setback as its flight schedule. The budget analyst whose July 1985 memorandum showed that NASA was aware of safety hazards in the solid rocket boosters said in a Washington Post article (16 March) that he had been asked to "deny the validity" of the memorandum in ensuing press enquiries. In the article, the analyst denounces NASA for perpetuating a stubborn optimism that flies in the face of its employees' conscientious warnings.

James C. Fletcher, nominated by the White House to take over as permanent administrator of NASA, is said to have had little enthusiasm for the job, and agreed to accept it only after considerable persuasion.

\section{US space programme}

\section{Delay not an unmixed curse}

\section{Washington}

WHILE it will be for Washington to decide how the US space programme will be continued in the post-Challenger era, the managers of individual projects are having to arrange that spacecraft poised for launch later in this year will survive long and still unknown delays on the ground. But uncertainty about the likely launch time may bring some unexpected benefits.

This may be the case with the Hubble Space Telescope, which was to have been launched next August. The deadline for the submission of research proposals has now been put back, which may give the Space Telescope Institute time to resolve the dispute about allocations of observing time (see Nature 318, 591; 1985).

The extra ground-time will also give engineers a chance to reduce the risk of "infant mortality" among the components of the telescope. This term refers to the failure of electronic parts which is common in the early weeks of space missions. The remedy is to switch on instruments before the launching of a satellite or space-probe, to "burn in" the electronic circuits.

Even so, James Welch, the NASA (National Aeronautics and Space Administration) programme director for the space telescope, says it will "not be a trivial matter" to store "this beast" on the ground until shuttle flights can be resumed. Mechanical systems designed to function in microgravity environments may not fare so well at $1 \mathrm{~g}$, while gyroscopes must be spun at regular intervals to prevent the pooling of lubricants and so as to redistribute weight. Similarly, the lightamplification assemblage of the faintobject camera, which has been designed and built by the European Space Agency, will have to be powered up every 30 days so as to maintain the internal vacuum.

A further difficulty is that career advancement is unlikely while spacecraft sit on the ground, which means that project leaders may be tempted to try their luck elsewhere. The way in which longterm space projects may suffer, even after launch, is illustrated by the Voyager missions to the outer planets, which have had six project managers since their inception more than a decade ago.

Nevertheless, the hope is that professionals who have already devoted a large part of their career to a project will not be driven away by a delay of another year or two. Torrence Johnson, head of the Galileo mission to Jupiter, says that people working of such projects have learned to cope with the frustration of delay.

Part of the Galileo team will be kept busy recalculating the trajectory of the spacecraft. The next launch window will be in June 1987. The plan is that Galileo should make ten orbits around Jupiter in a period of 20 months, but all the orbits will be different from each other so as to maximize the number of jovian moons encountered. In a celestial version of a 12-cushion billiards shot, the spacecraft will be helped on its way by the gravitational influence of successive moons. 